\title{
Knowledge of Causes of Maternal Deaths and Maternal Health Seeking Behaviour in Nigeria
}

\section{Ayotunde Titilayo ${ }^{1, a, b}$, Martin E. Palamuleni ${ }^{a}$ and Olusola Omisakin ${ }^{b}$}

${ }^{\text {a }}$ Population Training and Research Unit, North West University, Mmabatho, South Africa

${ }^{b}$ Demography and Social Statistics Department, Obafemi Awolowo University, Ile-Ife, Nigeria

\section{Abstract}

Nigeria has one of the highest maternal mortality rates in the world. The aim of this study is to examine the influence of women's knowledge of maternal death on their health seeking behaviour during pregnancy and childbirth. The study extracted and utilized respondents who had childbirth within three years prior to 2013 Nigeria Demographic and Health Survey. Bivariate analysis and logistic regressions were used to assess the association between knowledge of maternal death, selected socio-economic factors and health seeking behaviour. The results reveal that $34 \%$ did not attend antenatal visits, $27 \%$ of the respondents initiated antenatal care in the first trimester of pregnancy and $63 \%$ had birth deliveries outside the health facility. This confirms that non-use of health facilities during pregnancy and delivery contributes to the high maternal mortality in Nigeria. The multivariate analysis indicates that the odds ratio of good health-seeking behaviour is significantly generally low among women who had poor knowledge about the causes of maternal death than those who had good knowledge. Other factors influencing maternal-health seeking behaviour are region, education and wealth status. Poor maternal health-seeking behaviour was high among women in the Northern region, the poor women and women who had low educational background. Emphasis should be placed on these factors in considering strategies to improve the maternal health care system in Nigeria.

Keywords: maternal deaths, health seeking behaviour, Nigeria

\footnotetext{
${ }^{1}$ Corresponding author email: liasuayotunde@gmail.com
} 


\section{Résumé}

Nigeria possède l'un des taux de mortalité maternelle plus élevés au monde. L'objectif de cette étude est d'examiner l'influence des connaissances féminines de décès maternel sur leur état de santé qui cherchent le comportement pendant la grossesse et accouchement. L'étude extrait et utilisé les répondants avaient l'accouchement dans les trois ans avant 2013 Nigeria Demographic and Health Survey. Analyse bivariée et régressions logistiques ont été utilisées pour évaluer l'association entre connaissance de décès maternel, de certains facteurs socioéconomiques et de santé recherche de comportement. Les résultats révèlent que $34 \%$ n'a pas assisté les visites prénatales, $27 \%$ des répondants ont initié des soins prénatals pendant le premier trimestre de la grossesse et $63 \%$ avaient des livraisons de la naissance à l'extérieur de l'établissement de santé. Cela confirme cette non-utilisation des établissements de santé pendant la grossesse et l'accouchement contribue à la forte mortalité maternelle au Nigeria. L'analyse multidimensionnelle indique que les chances de bon comportement de recours est significativement plus faible chez les femmes ayant un manque de connaissances sur les causes de décès maternel que ceux qui ont de bonnes connaissances de $58 \%$. Autres facteurs influant sur le comportement de recherche santé maternelle sont la région, l'éducation et l'état de la richesse. Bon comportement maternel de recherche de la santé a été élevée chez les femmes dans le nord du pays, les femmes pauvres et les femmes ayant un faible niveau de formation. Ces facteurs doivent être considérés dans l'élaboration de stratégies pour améliorer le système de soins de santé maternels au Nigeria.

Mots-clés: mortalité maternelle, les comportements de recherche santé, Nigéria

\section{Introduction}

Every day somewhere in the world, a woman dies while pregnant or during 42 days after termination of pregnancy as a result of conditions traceable to the pregnancy or the way the pregnancy has been managed. Statistics on maternal death are important parameter for assessing the health status of a country, especially in developing countries where the highest cases of maternal mortality have been found. The differential in rates and skewness in the global distribution of maternal mortality rate are good indicators that some important maternal health determinants are lacking in certain areas of the world. Of all pregnancy or child birth related death, close to 95 per cent are found in Africa and Asia countries of the world (World Health Organization, 20I2). Many factors which include weak health care delivery systems, birth deliveries taking place in the home or out of the proper health facility where such births were not attended to by qualified health personnel; and even some of the available health institutions for one reason or the other lack trained and qualified personnel to handle deliveries have been identified with the high rate of maternal morbidity and death in these places. The impact of high quality and accessible health care has 
been so felt in the developed countries where only negligible per cent of less than I per cent of maternal death occurs (Okechukwu, 20I3).

Though literature is full of factors responsible for the rate of maternal mortality and series of efforts to curb it, but despite all these, the present maternal mortality rate in this part of the world is still unacceptably high. If good maternal health seeking behaviour and utilization health services have been found in positive association with improved maternal health outcomes (Babalola \& Fatusi, 2009), then effort to understand the determinants of maternal health seeking behaviour and maternal health use cannot be overemphasized. Knowing fully well that knowledge and awareness precede such preventive measures as health-seeking behaviour of people, then all efforts to study the link between women's awareness and knowledge of dangers attached to pregnancy and women's attitude towards maternal health seeking will do a great deal in solving this menace of maternal mortality. Hence this study therefore proposes to investigate the relationship between knowledge of the risk factors of maternal death and maternal health seeking behaviour in Nigeria.

\section{Literature review}

Though the risk factors of maternal death are numerous in less developed countries, while some of the direct causes like haemorrhage, eclampsia or hypertensive disorder of pregnancy, normal delivery problem and complication of abortion accounted for not less than $75 \%$ of maternal mortality, the indirect causes like other illnesses, latent infections like malaria, anaemia, tuberculosis and hepatisis that aggravated by pregnancy accounted for the remaining $25 \%$ maternal deaths (Merson, Robert \& Anne, 2006; Global One, 2015). When there is no adequate health care, the above health situations can develop into temporary or permanent morbidity. Women could suffer from obstetric fistula, pelvic inflammatory disease, reproductive tract infection or infertility, when and where the situations are not well-managed, it could eventually result in maternal death (Global One, 2015) during delivery or within 42 days after birth. Also important in the causes of maternal deaths are some direct or indirect social factors like early and late motherhood, frequency of antenatal attendance, pregnancies too close and higher fertility level among others (WHO \& UNICEF, 1996; Onwuhafua, Onwuhafua \& Adze, 2000; Magadi, 200I).

Nigeria being one of the nations of the world with the worst statistics on maternal death (Global One, 2015). Over many decades, maternal mortality rates in Nigeria have been fluctuating between well over 1200 and 500 maternal deaths per 100,000 live births (Harrison, 1990; Okonofua \& Illumoka, 1992; Harrison, 1997; FMOH, 2000; Onwuhafua, Onwuhafua \& Adze, 2000; Inegbenebor, 2007; Global One, 20I5). In fact, in terms of the frequency of occurrence of maternal deaths, the country has taken the eighth position among other sub-Saharan Africa countries and the second in the world after India (Global One, 2015). Although maternal mortality rate declined from 800 deaths per 100,000 live births to 545 deaths per 100,000 live births between 
2003 and 2008, most recent 20/3 nationwide Demographic and Health Survey shows that Nigeria experience 576 maternal deaths per 100,000 live births in 2013, a significant increase from the maternal mortality ratio recorded in 2008. Maternal deaths in Nigeria constitute 32\% of all deaths among women of reproductive age 15-49 in the country.

The fifth Millennium Development Goals (MDG) is concerned at process of making better maternal health and one of the principal targets of this goal is to lower maternal mortality ratio by three-quarters (75\%) in 2015. In Nigeria this translates to reducing MMR from I 200 in 1990 to about 250 deaths per 100,000 live births in 2015 . Unfortunately, the past trends and current level of maternal deaths in Nigeria only indicates some unimpressive achievements. Achieving the fifth goal of MDG target has always been like a mirage in the desert in Nigeria. There is no likelihood of attaining the fifth MDG by the 2015 deadline. However, government and other stakeholders should not relent in their good efforts channeling to provide quality, accessible and affordable health and social care services for improving the health status of women. So therefore, all these afore mentioned maternal death statistics justify all efforts supporting the move to increase maternal health and social care and reduce death among this highly vulnerable population in Nigeria.

Antenatal care is critical for successful childbirth and positive health outcomes after delivery. The health care and health education received by pregnant women before, during and after delivery has implications for the survival and well-being of both the women and their babies.
Antenatal care is essential for timely detection and prompt attention to complications as well as disease prevention. Shortage of maternal health care services at this stage may increase the risks of maternal morbidity and mortality (Human Right Watch, 20/4). During antenatal care, women also have access to health tips and counselling services that enable them to exhibit positive health behaviours. In order to ensure optimum health care during pregnancy, the World Health Organization

recommended at least four (4) antenatal care visits for pregnant women without complication, while women who experience complications may require more visits (NPC \& ICF Macro, 20I3). The place of delivery and quality of health care provider are also important in avoiding the occurrences of maternal death. In other words, the probability that a mother's health will become affected depends on timing of first antenatal visit, number of visit, whether the birth took place in a health facility or non-health facility and whether the birth was attended by skilled or unskilled health workers.

In Nigeria, non-utilization of health care services is a strong cause of the high frequency of maternal deaths in the country (NPC \& ICF Macro, 20I3). A recent report shows that $39 \%$ of women do not attend antenatal care from a skilled health provider, $63 \%$ of births occurred at home rather than in a health facility and just $38 \%$ of all birth deliveries were attended by a skilled birth assistant, the rest being from sources where the safety of women are not guaranteed (NPC \& ICF Macro, 2013). 
Studies on health-seeking behaviour of women in Nigeria have shown the impact of socio-economic characteristics like age, birth order, place of residence, level of education and wealth status on the utilization of health care services (NPC \& ICF Macro, 20I3; Okechukwu, 2013; Global One, 2015). For example, women age 20-34 were found with higher likelihood of using antenatal care services than women under age 20 and 35-49. Also, rural women and women with many children were less likely to attend antenatal care compared with urban women and those of lower parity (NPC \& ICF Macro, 2013; Okechukwu, 20I3; Global One, 2015). Certain other factors have also been documented as barriers to non-utilization of health care services in Nigeria including distance to health facility, cost of transportation, treatment cost, absence of health care provider at the health facility, poor quality of health care, absence of female health care provider and so on (NPC \& ICF Macro, 20I3; Okechukwu, 20I3).

Since nobody wants to deliberately die, not even in pregnancy or childbirth, irrespective of socio-economic status or other factors, if women had knowledge of the causes of maternal deaths, the present study assumes that they (pregnant women) would exhibit great precautions that would lead to appreciable reduction in maternal mortality. Despite the existence of many studies on maternal health issues, no known study has examined how women's knowledge and awareness of the causes of maternal death which is an important section during antenatal discussion affects their health-seeking behaviour. Hence, this study adds more to the existing literature by analyzing the relationship between knowledge of causes of maternal deaths and maternal health-seeking behaviour in Nigeria. This would serve as another eyes opener for the policy makers about other channels of public health strategies that can increase utilization of antenatal care and choice of place of birth delivery in Nigeria.

\section{Objectives}

This study has three objectives namely, (i) to examine the level of knowledge of women about the causes of maternal death; (ii) to determine the health-seeking behaviour of women during pregnancy (timing of first and number of antenatal visit) and for childbirth (place of delivery), and (iii) to explore the relationship between level of knowledge of causes of maternal death and health-seeking behaviour of women.

\section{Method and Materials}

\section{Study area}

The study area was Nigeria. It is the largest country in Africa with a population above 160 million individuals and located in Western hemisphere of the continent. The country is sub-divided into six sub-regions with 36 states and a Federal Capital Territory and a total of 774 constitutionally identifiable local government areas at the grass root levels. Nigeria is a country with a considerable human and natural endowment, but due to management problems and other administrative issues the country remains undeveloped with highly impoverished and rural population. The health profile of the country is generally poor and witnessed by a very low life expectancy at birth, poor maternal and infant health care services. 


\section{Study design and sample size}

The data for the study were extracted from a secondary source of the most current 2013 Nigeria Demographic and Health Survey (NDHS) individual recode dataset. The study was a nationally represented cross-sectional survey. It interviewed 38,948 women's socioeconomic, demographic and health statistics. From the total respondents of the $2013 \mathrm{NDHS}$, the present study used a weighted total respondent of 16,610 women, aged $15-49$ years $(42.6 \%$ of the total respondents) who had ever given birth within the last three years to the survey. Respondents who had childbirth longer than three years to the survey and those who never had childbirth experience were dropped from the analysis for this study.

\section{Dependent variable}

The dependent variable of the study was maternal health seeking behaviour of women. To measure maternal health seeking behaviour appropriately, the NDHS asked various questions but in this study three variables were utilized, namely; timing of first antenatal visit (during first, second, or third trimester), total number of antenatal visit (never, less than four times or four or more times) and place of delivery (private hospital, government hospital or home/faith clinic/TBA) to measure maternal health seeking behaviour in the study. For a respondent to qualify for a good maternal health seeking behaviour in the study such women must have made the first antenatal visit within the first trimester period, must have reported not less than four visits for antenatal and finally must have delivered in a government hospital.

\section{Independent variables}

The independent variables are age of respondents; place of residence; Region; Respondents' Education; Religion; Wealth status; Children Ever Born; Age at first birth; Partners' educational level and knowledge of causes of maternal death.

All the independent variables were categorized as follows: Age of respondents was categorized as $(15-19,20-24,25-29$, $30-34,35-39,40-44,45-49)$; place of residence (Urban and Rural); Region (North East, North West, North Central, South East, South West and South South); Respondents' Education (No, Primary, Secondary and Higher); and Partners' educational level (No, Primary, Secondary and Higher). To make analysis and interpretation simpler and more meaningful, some variables were regrouped from their original categories in the dataset. The following are the variables that were regrouped Children Ever Born (I-4 and more than 4); Age at first Birth (Less than 20 years and 20 years or more); Wealth status (Poor, Middle and Rich); Religion (Christian, Islam and Traditional/Others).

The 2013 Nigeria Demographic and Health Survey has no direct question on knowledge of the risk factors of maternal death. As such the variable knowledge of causes of maternal death was computed from the following two questions "told of complications of pregnancy" during antenatal visit and whether respondent's sibling ever experienced maternal death. The responses to these two questions are binary $\left(\right.$ Yes $=I$ and $\left.\mathrm{No}_{0}=0\right)$ and the new 
variable was generated by combining the two variables. The score of the combined variable ranges from 0 to 2 , therefore the knowledge of causes of maternal death was categorized as poor if the score equals 0 and good if otherwise.

\section{Data analysis}

The study employed three levels of data analysis were. The first level involved descriptive univariate analysis whereby, respondents' background characteristics were analysed using frequency and percentage distributions and were depicted in tabular form. The second level of analysis employed bivariate analysis to examine the association between independent variables and the dependent variable. In this regard, chi-square test at $\mathrm{p}-$ values of less than 0.01 and 0.05 were employed to test the significance of the relationship. Lastly, in the third level, the impact of knowledge of causes of maternal death and other background characteristics of women on health seeking behaviour of respondents was examined using binary logistic regression. The logistic regression models are given by

$$
\begin{aligned}
& \operatorname{Logit}(\mathrm{pi})=\log \left[\frac{p_{i}}{1-p_{i}}\right]=\alpha+\beta_{1} \mathrm{X}_{1 i} \\
& {\left[\frac{p_{i}}{1-p_{i}}\right]=\alpha+\beta_{1} \mathrm{X}_{1 i}+\beta_{2} \mathrm{X}_{2 i}}
\end{aligned}
$$

$\operatorname{Logit}(\mathrm{pi})=\log \left[\frac{p_{i}}{1-p_{i}}\right]=\alpha+\beta_{1} \mathrm{X}_{1 i}+\beta_{2} \mathrm{X}_{2 i}+\beta_{3} \mathrm{X}_{3 i} \ldots$

$\operatorname{Logit}(\mathrm{pi})=\log \left[\frac{p_{i}}{1-p_{i}}\right]=\alpha+\beta_{1} \mathrm{X}_{1 i}+\beta_{2} \mathrm{X}_{2 i}+\beta_{3} \mathrm{X}_{3 i}+\beta_{4} \mathrm{X}_{4 i}$

(model 4)

Where:

pi = Probability of having good maternal health seeking behaviour,

$\mathrm{I}$-pi $=$ probability of not having good maternal health seeking behaviour,

$\alpha=$ Constant,

$\beta$,s $=$ Coefficients associated with independent variables,

$X_{s}=$ Covariates in the study.

\section{Results of the analysis}

Table I depicts the background characteristics of the respondents. The sample population reflects the young age population of the country, fairly more than seven in every ten are less than thirty five years old. About two-third (65\%) of the women are residents of rural areas, the majority of the respondents were from Northern region (68\%) while less than thirty-three percent are from the Southern region (32.1\%). Religion affiliation distribution reveals majority of the 
respondents belong to Islamic faith. The educational background indicates that the respondents with low level of education were at least twice as many as those with higher level of education $(67 \%$ and $33 \%$ respectively). Close to six-tenth (58\%) of the women had partners with low level of education. The distribution by wealth index shows that nearly sixty-five percent of the total respondents were either in poor or middle class while less than four in ten respondents was in the rich category. Total number of children ever born by respondents revealed that majority $64 \%$ had four or less births, this follows the declining pattern of fertility in the country.

Slightly less than sixty percent of the respondents had first birth experience before reaching age twenty years while close to sixty-five percent had one to four children as at the time of the survey. In terms of health-seeking behaviour during the last pregnancy, $53 \%$ of the women had four or more antenatal visit in last pregnancy, 34\% made no visit and 13\% had less than four antenatal visits. Similarly, timing of first antenatal visit shows that only $27 \%$ of the women had their first antenatal visit in the first trimester of pregnancy, the majority of the women $(62 \%)$ had their first antenatal visit in the second trimester and $11 \%$ of them had their first antenatal visit in the third trimester. Out of the total respondents, barely $24 \%$ delivered in government hospitals, while a little above ten percent (13\%) had their last birth at a private hospital and the majority (63\%) had their last birth at other places such as private or faith homes and some at traditional birth homes. About one-third (33\%) of the women demonstrated poor knowledge of causes of maternal deaths, while two-third $(67 \%)$ of the women displayed good knowledge

Table I Socioeconomic, demographic and behavioural characteristics of respondents

\begin{tabular}{|l|r|r|}
\hline Variables & Frequency (n) & Per cent (\%) \\
\hline Age groups & & \\
\hline $15-19$ & 1255 & 7.6 \\
\hline $20-24$ & 3579 & 21.5 \\
\hline $25-29$ & 4543 & 27.4 \\
\hline $30-34$ & 3402 & 20.5 \\
\hline $35-39$ & 2395 & 14.4 \\
\hline $40-44$ & 1062 & 6.4 \\
\hline $45-49$ & 375 & 2.3 \\
\hline Place of residence & & \\
\hline Urban & 5802 & 34.9 \\
\hline
\end{tabular}


African Population Studies Vol. 29, No. 2, Supplement, 2015

\begin{tabular}{|c|c|c|}
\hline Variables & Frequency $(n)$ & Per cent (\%) \\
\hline Rural & 10808 & 65.1 \\
\hline \multicolumn{3}{|l|}{ Religion†t } \\
\hline Christian & 6136 & 37.2 \\
\hline Islam & 10219 & 61.9 \\
\hline Traditional & 155 & 0.9 \\
\hline \multicolumn{3}{|l|}{ Region } \\
\hline North Central & 2319 & 14 \\
\hline North East & 2819 & 17 \\
\hline North West & 6146 & 37 \\
\hline South East & 1427 & 8.6 \\
\hline South South & 1593 & 9.6 \\
\hline South West & 2307 & 13.9 \\
\hline \multicolumn{3}{|l|}{ Educational level } \\
\hline No & 7988 & 48.1 \\
\hline Primary & 3113 & 18.7 \\
\hline Secondary & 4456 & 26.8 \\
\hline Higher & 1053 & 6.3 \\
\hline \multicolumn{3}{|l|}{ Wealth Index } \\
\hline Poor & 7659 & 46.1 \\
\hline Middle & 3173 & 19.1 \\
\hline Rich & 5778 & 34.8 \\
\hline \multicolumn{3}{|l|}{ Age at first birth } \\
\hline Less 20 years & 9842 & 59.3 \\
\hline 20 years or more & 6768 & 40.7 \\
\hline \multicolumn{3}{|l|}{ Children ever born } \\
\hline $\mathrm{I}-4$ & 10625 & 64 \\
\hline$>4$ & 5985 & 36 \\
\hline \multicolumn{3}{|c|}{ Knowledge of causes of maternal death†t } \\
\hline Poor & 3472 & 31.9 \\
\hline Good & 7405 & 68.1 \\
\hline Partner's educational level†† & & \\
\hline
\end{tabular}


African Population Studies Vol. 29, No. 2, Supplement, 2015

\begin{tabular}{|l|r|r|}
\hline Variables & Frequency (n) & Per cent (\%) \\
\hline No & 6293 & 39.1 \\
\hline Primary & 2971 & 18.5 \\
\hline Secondary & 4753 & 29.5 \\
\hline Higher & 2075 & 12.9 \\
\hline Number of Antenatal Visit in last Pregnancytt & & \\
\hline No visit & 5604 & 33.9 \\
\hline Less than 4 & 2098 & 12.7 \\
\hline 4 or more & 8805 & 53.3 \\
\hline Timing of first Antenatal Visitt† & & \\
\hline Ist Trimester & 2932 & 26.9 \\
\hline 2nd Trimester & 6743 & 61.8 \\
\hline 3rd Trimester & 1233 & 11.3 \\
\hline Place of Deliveryt† & & \\
\hline Government Hospital & 3898 & 23.5 \\
\hline Private Hospital & 2207 & 13.3 \\
\hline (Others) Faith clinic/TBA & 10477 & 63.2 \\
\hline
\end{tabular}

t† Responses less than the total respondents $(16,610)$

\section{Bivariate analyses}

Table 2 depicts the relationship between socio-demographic background characteristics of respondents and their health seeking behaviour. Being categorical variables, the chi-square statistical test shows the relationship between the dependent and independent variables. There is a statistically significant relationship between all the background characteristics and the dependent variable $(p<0.00 I)$. Respondents' ages, ages at birth, educational level, wealth index, partner's educational level and respondent's level of knowledge of risk factors of maternal death vary positively with good maternal health seeking behaviour.

Respondents who are Christians, who reside in urban areas and those who reside in the Southern part of Nigeria and those who have a good knowledge of causes of maternal death had a better attitude towards maternal health seeking than their counterparts who live in rural areas and those who are in the Northern part of Nigeria respectively. As depicted in the table, women who had more than four children were shown having poor attitude towards maternal health seeking than their counterparts who had four or less children 
Table 2 Per cent distribution of women who had birth within the last three years by maternal health seeking behaviour.

\begin{tabular}{|c|c|c|c|c|}
\hline \multirow[t]{2}{*}{ Variables/Categories } & \multicolumn{3}{|c|}{ Maternal Health Seeking Behaviour } & \multirow[t]{2}{*}{ Significance test } \\
\hline & Good & Poor & Total & \\
\hline \multicolumn{4}{|l|}{ Age groups } & \multirow[t]{8}{*}{$54.637^{* * * *}$} \\
\hline $15-19$ & 25.6 & 74.4 & 664 & \\
\hline $20-24$ & 32.7 & 67.3 & 2281 & \\
\hline $25-29$ & 36.9 & 63.1 & 3049 & \\
\hline $30-34$ & 38.7 & 61.3 & 2363 & \\
\hline \multirow{3}{*}{$\begin{array}{l}35-39 \\
40-44 \\
45-49\end{array}$} & 36.9 & 63.1 & 1626 & \\
\hline & 33.9 & 66.1 & 663 & \\
\hline & 29.5 & 70.5 & 217 & \\
\hline \multirow{3}{*}{$\begin{array}{l}\text { Place of residence } \\
\text { Urban } \\
\text { Rural }\end{array}$} & & & & \multirow[t]{3}{*}{$367.703 * * *$} \\
\hline & 44.7 & 55.3 & 5128 & \\
\hline & 27.1 & 72.9 & 5733 & \\
\hline \multirow{4}{*}{$\begin{array}{l}\text { Religion } \\
\text { Christian } \\
\text { Islam } \\
\text { Traditional }\end{array}$} & & & & \multirow[t]{4}{*}{482.913 **** } \\
\hline & 45.8 & 54.2 & 5199 & \\
\hline & 25.6 & 74.4 & 5531 & \\
\hline & 27.5 & 72.5 & 69 & \\
\hline \multirow{7}{*}{$\begin{array}{l}\text { Region } \\
\text { North Central } \\
\text { North East } \\
\text { North West } \\
\text { South East } \\
\text { South South } \\
\text { South West }\end{array}$} & & & & \multirow[t]{7}{*}{$779.129 * * * *$} \\
\hline & 41.0 & 59.0 & 1696 & \\
\hline & 24.2 & 75.8 & $|70|$ & \\
\hline & 18.0 & 82.0 & 2725 & \\
\hline & 46.8 & 53.2 & 1344 & \\
\hline & 45.4 & 54.6 & 1240 & \\
\hline & 48.9 & 51.1 & 2155 & \\
\hline \multirow{5}{*}{$\begin{array}{l}\text { Educational level } \\
\text { No } \\
\text { Primary } \\
\text { Secondary } \\
\text { Higher }\end{array}$} & & & & \multirow[t]{5}{*}{ II $28.722 * * *$} \\
\hline & 16.8 & 83.2 & 3367 & \\
\hline & 30.4 & 69.6 & 2447 & \\
\hline & 46.5 & 53.5 & 4021 & \\
\hline & 64.3 & 35.7 & 1026 & \\
\hline \multirow{4}{*}{$\begin{array}{l}\text { Wealth Index } \\
\text { Poor } \\
\text { Middle } \\
\text { Rich }\end{array}$} & & & & \multirow[t]{4}{*}{969.238 **** } \\
\hline & 15.7 & 84.3 & 3175 & \\
\hline & 31.6 & 68.4 & 2367 & \\
\hline & 48.8 & 51.2 & 5320 & \\
\hline
\end{tabular}


African Population Studies Vol. 29, No. 2, Supplement, 2015

\begin{tabular}{|c|c|c|c|c|}
\hline \multirow[t]{2}{*}{ Variables/Categories } & \multicolumn{3}{|c|}{ Maternal Health Seeking Behaviour } & \multirow[t]{2}{*}{ Significance test } \\
\hline & Good & Poor & Total & \\
\hline \multirow{3}{*}{$\begin{array}{l}\text { Age at birth } \\
<20 \\
\geq 20\end{array}$} & & & & \multirow[t]{3}{*}{$473.815 * * *$} \\
\hline & 25.6 & 74.4 & 5561 & \\
\hline & 45.6 & 54.4 & 5300 & \\
\hline \multirow{4}{*}{$\begin{array}{l}\text { Knowledge of causes of } \\
\text { maternal death } \\
\text { Poor } \\
\text { Good }\end{array}$} & & & & \multirow[t]{4}{*}{$345.55 I^{* * * *}$} \\
\hline & & & & \\
\hline & 22.9 & 77.1 & 3435 & \\
\hline & 41.3 & 58.7 & 7356 & \\
\hline \multicolumn{4}{|l|}{ Partner's educational level } & \multirow[t]{5}{*}{$819.595 * * *$} \\
\hline \multirow{4}{*}{$\begin{array}{l}\text { No } \\
\text { Primary } \\
\text { Secondary } \\
\text { Higher }\end{array}$} & 15.1 & 84.9 & 2374 & \\
\hline & 30.6 & 69.4 & 2189 & \\
\hline & 40.5 & 59.5 & 4015 & \\
\hline & 55.1 & 44.9 & 1893 & \\
\hline \multirow{3}{*}{$\begin{array}{l}\text { Children Ever Born } \\
I-4 \\
>4\end{array}$} & & & & \multirow[t]{3}{*}{$|3| .10 \mid * * *$} \\
\hline & 39.0 & 61.0 & 7346 & \\
\hline & 27.8 & 72.2 & 3516 & \\
\hline
\end{tabular}

**** $\mathrm{p}<0.001$

\section{Multivariate analyses}

In Table 3, results of binary logistic regression analyses for the relationship between maternal health-seeking behaviour and its covariates are shown using three distinct models. Model I examines the relationship between women's knowledge about the causes of maternal death and maternal healthseeking behaviour. The result indicates that there is a significant relation between the two variables. Women who had poor knowledge of risk factors of maternal death were found to be 0.42 less likely to have good maternal health-seeking behavior than those in the reference category (respondents who had good knowledge of causes of maternal death). Model 2 controls for the demographic attributes of the respondents and as revealed in the table, women with poor knowledge of causes of maternal death were still found to be 0.55 less likely to have good maternal health-seeking behavior than their other counterparts who had good knowledge of causes of maternal death. Place of usual residence, region and number of children ever born were significantly related to health seeking behavior. The odds of maternal health seeking behavior among women who reside in urban areas, who were from North Central, South East and South South and who had given birth to about four children was found to be higher when compared with their respective counterparts. The odds of good healthseeking behaviour among women with poor knowledge of maternal death improved quite substantially from 0.42 in first Model to 0.62 in Model 3 when the net effects of socio-economic variables were introduced. Significant positive relationship exists between respondents' educational 
level, their wealth index and their partners' educational attainment. The odds ratio of maternal health seeking behavior was significantly lower among women with less education and those from poor and middle wealth indexes. There is sufficient significant statistical evidence to conclude that knowledge of the causes of maternal death has a significant impact on maternal health-seeking behaviour in the study area. Model 4 also indicates a less likelihood (0.63) of maternal health seeking behavior among women who had poor knowledge of causes of maternal death when compared with their counterparts who had good knowledge of risk factors of maternal death. That is while controlling for all the possible confounding demographic and socio-economic variables, the odds of maternal health seeking behaviour among the respondents increased to 0.63 from 0.42 in model 1 . The net interaction of both demographic and socio-economic characteristics revealed a significant relationship between place of residence, region, age at first birth, respondents' educational level, wealth index and paternal educational level and health-seeking behaviour.

Table 3 Odds of good maternal health seeking behaviour among women who had at least one birth within the last three years prior to 2013 NDHS

\begin{tabular}{|c|c|c|c|c|}
\hline Variables/Categories & Model I & Model 2 & Model 3 & Model 4 \\
\hline \multirow{3}{*}{$\begin{array}{l}\text { Knowledge of causes of } \\
\text { maternal death } \\
\text { Poor } \\
\text { Good } \\
\text { RC }\end{array}$} & & & & \\
\hline & $0.423 * * *$ & $0.552 * * *$ & $0.615 * * *$ & $0.632 * * *$ \\
\hline & 1.000 & 1.000 & 1.000 & 1.000 \\
\hline \multicolumn{5}{|l|}{ Demographic variables } \\
\hline \multicolumn{5}{|l|}{ Age } \\
\hline \multirow{7}{*}{$\begin{array}{l}15-19 \\
20-24 \\
25-29 \\
30-34 \\
35-39 \\
40-44 \\
45-49 \mathrm{RC}\end{array}$} & & 1.015 & & 1.102 \\
\hline & & 1.077 & & 1.080 \\
\hline & & 1.022 & & 0.932 \\
\hline & & 1.120 & & 0.972 \\
\hline & & 1.122 & & 0.987 \\
\hline & & 1.032 & & 0.962 \\
\hline & & 1.000 & & 1.000 \\
\hline \multirow{3}{*}{$\begin{array}{l}\text { Place of Residence } \\
\text { Urban } \\
\text { Rural RC }\end{array}$} & & & & \\
\hline & & $1.667 * * *$ & & $1.099 *$ \\
\hline & & 1.000 & & 1.000 \\
\hline \multirow{7}{*}{$\begin{array}{l}\text { Region } \\
\text { North Central } \\
\text { North East } \\
\text { North West } \\
\text { South East } \\
\text { South South } \\
\text { South West }{ }^{R C}\end{array}$} & & & & \\
\hline & & $1.148 *$ & & $1.186 * * *$ \\
\hline & & $0.615 * * *$ & & $0.892 *$ \\
\hline & & $0.399 * * *$ & & $0.567 * * *$ \\
\hline & & 1.106 & & 1.092 \\
\hline & & $1.220 * * *$ & & 0.763 \\
\hline & & 1.000 & & 1.000 \\
\hline Age at first birth & & & & \\
\hline
\end{tabular}




\begin{tabular}{|c|c|c|c|c|}
\hline Variables/ Categories & Model I & Model 2 & Model 3 & Model 4 \\
\hline \multirow{2}{*}{$\begin{array}{l}\text { Less } 20 \\
20 \text { or more }{ }^{R C}\end{array}$} & & 0.645 & & $0.734 * * *$ \\
\hline & & 1.000 & & 1.000 \\
\hline \multirow{3}{*}{$\begin{array}{l}\text { Children ever born } \\
\mathrm{I}-4 \\
>4^{\mathrm{RC}}\end{array}$} & & & & \\
\hline & & $1.269 * * *$ & & 0.990 \\
\hline & & 1.000 & & 1.000 \\
\hline \multicolumn{5}{|c|}{ Socio-economic Variables } \\
\hline \multirow{5}{*}{$\begin{array}{l}\text { Respondent Education } \\
\text { No } \\
\text { Primary } \\
\text { Secondary } \\
\text { Higher }{ }^{R C}\end{array}$} & & & & \\
\hline & & & $0.392 * * * *$ & $0.473 * * *$ \\
\hline & & & $0.512 * * *$ & $0.587 * * *$ \\
\hline & & & $0.708 * * *$ & $0.764 * * *$ \\
\hline & & & 1.000 & 1.000 \\
\hline \multirow{4}{*}{$\begin{array}{l}\text { Wealth } \\
\text { Poor } \\
\text { Middle } \\
\text { Rich }{ }^{R C}\end{array}$} & & & & \\
\hline & & & $0.414 * * *$ & $0.479 * * *$ \\
\hline & & & $0.706 * * *$ & $0.742 * * *$ \\
\hline & & & 1.000 & 1.000 \\
\hline \multirow{4}{*}{$\begin{array}{l}\text { Religion } \\
\text { Christian } \\
\text { Islam } \\
\text { Traditional }^{R C}\end{array}$} & & & & \\
\hline & & & 0.954 & 1.039 \\
\hline & & & 0.658 & 0.880 \\
\hline & & & 1.000 & 1.000 \\
\hline \multirow{5}{*}{$\begin{array}{l}\text { Partner's education } \\
\text { No } \\
\text { Primary } \\
\text { Secondary } \\
\text { Higher }{ }^{R C} \\
\end{array}$} & & & & \\
\hline & & & $0.525 * * *$ & $0.530 * * *$ \\
\hline & & & $0.66 I^{* * *}$ & $0.633 * * *$ \\
\hline & & & $0.700 * * *$ & $0.67 \mid$ **** \\
\hline & & & 1.000 & 1.000 \\
\hline \multirow{3}{*}{$\begin{array}{l}\text {-2log likelihood } \\
\text { Chi-square (df) } \\
\text { Sig. }\end{array}$} & 13670.485 & 12732.952 & 11826.129 & 11674.076 \\
\hline & $360.463(I)$ & 1297.997(I5) & $1603.395(\mathrm{II})$ & $1755.448(25)$ \\
\hline & 0.000 & 0.000 & 0.000 & 0.000 \\
\hline
\end{tabular}

This is a probable suggestion that socioeconomic variables of women in Nigeria have a significant impact on whether or not they will seek maternal health. It was revealed that women who reside in Northern part of the country were significantly less likely to have good healthseeking behaviour than their counterparts who reside in the Southern part of Nigeria. Furthermore, the odds of maternal healthseeking behaviour among less educated women was significantly 0.57 less likely than those women who were of higher educational status.
The odds of good maternal healthseeking behaviour are nearly equal for all categories of age. Current age of respondents has no significant effect in determining health-seeking behaviour of women among the study population in any of the models. However, good healthseeking behaviour varied significantly by region where the odds ratio of good health-seeking behaviour was relatively higher in North Central of the country than any other five regions. Also, by educational level, women who had low education were less likely to exhibit good health-seeking behaviour than those who had high 
education. The odds of good healthseeking behaviour were 0.48 less likely among poor women and 0.74 less likely among middle women when compared with women in rich category. Furthermore, the odds of good maternal health-seeking behaviour was 0.73 less likely among women whose age at first birth were less than 20 years compared to women whose age at first birth were 20 years or more. Women whose age at first birth were 20 years or more were significantly more likely to exhibit good health-seeking behaviour than their other counterparts, whose age at first birth were less than 20 years (Model 4).

As regards the partner's education, the current results in Model 4 reveals that women whose partners had no formal education and those who had primary education were significantly 0.53 and 0.63 less likely to exhibit good health-seeking behaviour compared to women whose partners had higher education.

\section{Discussion and Conclusion}

The statistics recorded for maternal mortality in Nigeria is worrisome. This prevalence has made the nation the eighth country in sub-Saharan Africa and second country world over with the highest cases of maternal mortality (Global One, 20I5). There are a number of reasons for this situation which can be dealt with practically. First and foremost, a lot of women in the country did not comply with health safety precautions that will guarantee safe deliveries and well-being of both infants and mothers before and during the postnatal period. Findings from this study reveal that relatively few $(27 \%)$ of the respondents initiated antenatal care in the first trimester of pregnancy, a significant number of the respondents either did not attend antenatal visit (34\%) or attended less than 4 times (13\%) and the majority $(63 \%)$ had birth deliveries outside the health facility including places like home, faith clinic and TBA. Little wonder it was reported that a significantly high proportion of women did not comply with WHO recommendation of minimum maternal health standard of four antenatal visits during pregnancy (NPC \& ICF Macro, 20I3). This finding of low antenatal visit among the respondents was in line with the finding in Babalola and Fatusi (2009) in their study where they reported that level of utilization of orthodox health care facilities for maternal care among women in Nigeria was low (Babalola \& Fatusi, 2009).

Secondly, lack of good maternal healthseeking behaviour was constantly high among certain groups of the respondents, especially women in the Northern region, who are poor and women who had low educational background, among which greater proportions of the respondents initiated antenatal visit in the second and third trimesters of pregnancy, attended antenatal visits less than four times and also delivered outside the health facilities. The p-values consistently showed that the afore-mentioned variables were significantly associated with maternal health-seeking behaviour among the study population. These findings are in agreement with those of various studies which have shown that socio-economic variables have impact on health care services utilization in Nigeria (Babalola \& Fatusi, 2009; NPC \& ICF Macro, 2013; Okechukwu, 20I3; Global One, 2015). 
Regional disparities in maternal health services have also been observed in other countries (Mekonnen \& Mekonnen, 2003; Mrisho et al., 2007; Makoka, 2009; Palamuleni, 20I I). The regional disparity in the use of maternal health facilities during birth delivery could be attributed to differential in the availability and accessibility of maternal health care facilities including the distance to the health care centre and culture.

The study again found that women with low educational background were more likely to exhibit poor maternal healthseeking behaviour than their counterparts with higher educational background. This result is line with findings from other studies (Tawiah, 20II; Kalule-Sabiti, Amoateng \& Ngake, 20I4). The higher likelihood of poor maternal health-seeking behaviour by women with low educational background may be as a result of limited appreciation or less sense of value by women with limited education in understanding the need for professional supervision during delivery. It is, sometimes, claimed that the relationship between female education and healthseeking behaviour may not be due to educational attainment per se, but rather due to women's exposure and mental ability which education may serve as a proxy. It is argued that analyses that do not control for childhood background may overstate the impact of education on health outcome.

Several determining factors have been put forward as to explain why educated mothers are less likely to deliver at home than uneducated mothers in the literature. Among such many reasons are I. Educated women may have greater decision making power on health related matters and also attach higher value to the welfare and their health. 2. Educated mothers will have more confidence in handling the officials and have the ability and willingness to travel outside the home to seek services. For it was expected that among other things that the decision making power within the household, awareness, knowledge and the acceptance of modern medical treatment and health care institutions of mothers should vary according to their levels of education.

Furthermore, the impact of knowledge about the causes of maternal death cannot be over-emphasized. Findings of this study revealed that compared to women who had poor knowledge about the causes of maternal death, those who had good knowledge were always more likely to exhibit good health-seeking behaviour in terms of the timing of the first antenatal visits which usually should commence in the first trimester of pregnancy, number of antenatal visits up to four or more times during pregnancy and birth deliveries attended by qualified health personnel in a health facilities. Even after adjusting for the effects of some socio-economic and demographic variables, the odds ratios and $\mathrm{p}$-value in our analyses showed that knowledge about the causes of maternal death continued to have both a positive and a significant impact on maternal healthseeking behaviour among the respondents. Supposedly, the respondents who showcased good knowledge are believed to be more sensitive to the health risks associated with pregnancy and have greater awareness about the different factors that often bring about the 
occurrences of maternal morbidity and mortality.

Reflecting on the above findings, the study concludes knowledge of risk factors of maternal death is a paramount predictor of maternal health seeking behaviour and that education and other sociodemographic variables are consistently undisputable predictors of maternal health seeking behaviour in Nigeria. Therefore, there is a need for awareness programmes that will create sufficient access to reproductive health information and education for the women both within and outside the health facility and thus, a drastic reduction in the occurrences of maternal death in Nigeria could be in place in the nearest future.

\section{Recommendations}

There are policies and programmes implications of the study in any country that seeks to improve maternal health services Nigeria inclusive. The outcome of the study indicates that there is need to improve and encourage the patronage of women who reside in the rural areas and perhaps those in Northern part of the country that do not use modern health facilities during pregnancy and delivery,. Secondly, raising women status in terms of education and socio-economic status is greatly needed. Thirdly, early child bearing should be discouraged and lastly, there should be encouragement for more and advanced studies to investigate factors that predispose women to not using modern health facilities during pregnancy and delivery as this would assist in revealing reasons for their choices of health seeking behaviour during pregnancy and delivery.
We suggest that these recommended future studies should employ a mixmethod of qualitative and quantitative research technique apart from being a multidisplinary studies.

\section{Limitations}

The study has several limitations, firstly, the use of secondary data for the analysis would have excluded some important variables such as distance between residence and nearest health facility, attitude and character of service providers towards clients, time spent before been attended to by the service providers and the cost of the services. These and many other factors have been found to influence decisions to use modern health facilities or not. Secondly, as expected with studies of this nature, the findings of this study are subjected to both conscious and unconscious human errors, misreporting and misinterpretation of information. Thirdly, definition of some of the concepts by the respondents may affect their responses and this may have effect on the final findings. As such, in comparing these results with similar studies, it is important to recognize that the definitions of concepts may differ from country to country. Lastly, due to cross sectional nature of the data utilized for the study, causation effect between independent and outcome variables cannot be over stressed.

\section{References}

Babalola, S. \& Fatusi, A. 2009. Determinants of use of maternal health services in Nigeria - looking beyond individual and household factors. BMC 
Pregnancy and Childbirth. 9(I), 43 http://www.biomedcentral.com/47I-

2393/9/43 doi.10.1/86//47I-2393-943.

FMOH. 2000. National Reproductive Health Policy (draft report). Federal Ministry of Health.

Global One. 2015. Maternal Health in

Nigeria: A Statistical Overview. http://www.globalone2015.org/wpcontent/uploads/20 I I/I I/MaternalHealth-in-Nigeria-Statistical-

Overview.pdf.

Harrison, K.A. 1990. Maternal mortality in

Nigeria. Paper presented at the International Conference on National Safe Motherhood sponsored by the Society of Gynaecology and Obstetrics of Nigeria, Abuja, Nigeria, Nicon Noga Hilton Hotel, September II-13, 1990.

Harrison, K.A. 1997. Maternal mortality in Nigeria: The Real Issues. African Journal of Reproductive Health; I (I):7-I3.

Human Right Watch, 2014. I've never experienced happiness: Child marriage in Malawi. http://www.hrw.org

Inegbenebor, U. 2007. Conceptual model for the prevention of maternal mortality in Nigeria. Tropical Doctor, 37(2): I04106.

Kalule-Sabiti I, Amoateng, Y.A. \& Ngake, M. 2014. The effect of sociodemographic factors on the utilization of mMaternal health care services in Uganda. African Population Studies, 28(I):5।5-525.

Magadi, M. 200I. Analysis of factors associated with maternal mortality in Kenyan hospitals. Journal of Biosocial Science, 33:375-389.

Makoka D 2009. Towards an understanding of regional disparities in social inequalities in maternal health in Malawi. African Health Sciences 9(4):234-240.

Mekonnen Y, Mekonnen A 2003. Factors influencing the use of maternal health care services in Ethiopia. Journal of Health Population and Nutrition $2 \mathrm{I}(4): 374-382$.

Merson, M.H., Robert, E.B. \& Anne, J.M. 2006. International Public Health: Diseases, Programs, Systems and Policies. London: Jones and Bertlett.

Mrisho M, Schellenberg JA, Mushi AK, Obrist B, Mshinda H, Tanner M, Schellenberg D 2007. Factors affecting home delivery in rural Tanzania. Tropical Medicine and International Health 12(7):862-872.

National Population Commission (NPC) [Nigeria] and ICF International, 2014. Nigeria Demographic and Health Survey 2013. National Population Commission (NPC) and ICF International, Abuja, Nigeria, and Rockville, Maryland, USA.

Onwuhafua, P.I., Onwuhafua, A. \& Adze, J. 2000. The challenge of reducing maternal mortality in Nigeria. International Journal of Gynecology and Obstetrics. 7I(3):2II-2I3.

Okechukwu, O.A. 2013. Perceived Challenges of Using Maternal Healthcare Services in Nigeria, Arts and Social Sciences Journal, Vol. 2013: ASSJ65.

Okonofua, F.E. \& Illumoka, T. 1992. Prevention of morbidity and mortality from induced and unsafe abortion in Nigeria. Report of a seminar presented to the Population Council, New York. 
Palamuleni, E.M. 20II. Determinants of non-institutional deliveries in Malawi. Malawi Medical Journal, 23(4): I04-108.

Tawiah E.O. 20I I. Maternal health care in five sub-Saharan African countries. African Population Studies 25(I): I-25. World Health Organization WHO and United Nations Children's Fund WHO \& UNICEF. 1996. Revised 1990 estimates of maternal mortality: A new approach by WHO and UNICEF. World Health Organisation and United Nations Children's Fund, Geneva. World Health Organization WHO. 2012. Trends in maternal mortality: 1990 to 2010: WHO, UNICEF, UNFPA and The World Bank estimates. World Health Organisation, Geneva 